\title{
Predictive value of disease severity on self-reported rating and quantitative measures of olfactory function outcomes after primary endoscopic sinus surgery. A prospective
} study*

\section{Friederike Minwegen', Jan P. Thomas', Manuel Bernal-Sprekelsen², Stefan Dazert ${ }^{1}$, Amir Minovi ${ }^{1}$}

Rhinology 52: 437-443, 2014 DOI:10.4193/Rhino14.043

' Department of Otorhinolaryngology, Head and Neck Surgery, Ruhr-University Bochum, St. Elisabeth Hospital, Bochum, Germany 2 Department of Otorhinolaryngology, Rhinology Unit and Smell Clinic, Hospital Clinic, Universitat de Barcelona, Barcelona, Spain

February 11, 2014

Accepted: June 14, 2014

\begin{abstract}
Background: This prospective study investigates the influence of primary Endoscopic Sinus Surgery (ESS) in patients with chronic rhinosinusitis (CRS) on olfactory function and on the patient's quality of life. We assess the role of preoperative disease severity measured by computed tomography (CT) scan in predicting outcome.
\end{abstract}

Methodology: Adults undergoing ESS were examined preoperatively $(n=92)$ and five months postoperatively. Coronal CT scans were evaluated referencing the Lund Mackay (LM) system. On the basis of the LM score, the collective was divided into two groups. We performed the olfactory test "Sniffin' Sticks" and handed out the specific health-related quality of life questionnaire SNOT-20.

Results: We could demonstrate that olfactory function of patients with strong opacification on CT scans improved by an average by 2.49 points more than olfactory function of patients with less severe disease. In terms of the self-reported rating of smell, the degree of amelioration differed significantly. Both groups showed an improvement in quality of life irrespective of severity of disease.

Conclusion: Mean olfactory function of patients with a high degree of disease in CT scan improved more than that of patients with less opacification on CT scan. Patient's subjective perception of smell impairment was in line with these findings.

Key words: olfaction, sinus surgery, quality of life, rhinosinusitis, endoscopy

\section{Introduction}

Overall, $14-53 \%$ of olfactory disorders are caused by inflammation of the nose or the paranasal sinus ${ }^{(1-4)}$. Accordingly, olfactory impairment is a frequent symptom in chronic rhinosinusitis (CRS). A number of studies have demonstrated rates of $48.5-83 \%$ of olfactory disorders in CRS ${ }^{(1,5-7)}$. Furthermore, the reduction or loss of smell is one of the four symptoms defining rhinosinusitis in adults ${ }^{(6)}$. Conductive loss and sensory-neural loss are both presumed to be responsible for the genesis of olfactory dysfunc-

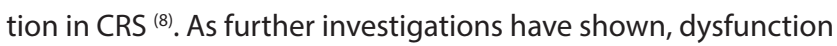

of smell impairs general and specific health-related quality of life ${ }^{(4,9-10)}$. Endoscopic Sinus Surgery (ESS), topic and systemic corticosteroids as well as leukotriene receptor antagonists are considered possible treatments, either alone or in combination ${ }^{(8)}$. Several studies have investigated nasal surgery as a treatment of olfactory dysfunction in patients with CRS. Improvement rates ranged between 23 and $85 \%{ }^{(1,11,12)}$. However, most of the investigations are based on the subjective rating of olfactory function, which is an inappropriate instrument to measure smell impairment ${ }^{(1,13)}$. Predictive factors of postoperative outcome 
which are easy to assess in the clinical context have not yet been well defined. There are few studies exploring the association between opacification in computed tomography (CT) scan and the outcome of nasal surgery in terms of olfactory function ${ }^{(14-18)}$. Only some of these studies use an olfactory test $(14,15,18)$.

To describe the severity of CRS before surgery, Lund and Mackay proposed a staging classification, which has been widely used and accepted. Depending on the severity of opacification in the preoperative CT scan, the Lund Mackay (LM) score is calculated. By comparing olfactory test results, Litvack et al. demonstrated that patients with anosmia and nasal polyps profit more by ESS than patients with hyposmia and nasal polyps, but neither CT score nor endoscopy score seemed able to predict postoperative results in terms of olfactory function ${ }^{(14)}$. Another study has shown a negative correlation of the LM score with preoperative olfactory test results, while there was no correlation with postoperative results or degree of change. Self-reported ratings and quantitative measures of olfactory function improved after surgery ${ }^{(15)}$.

The purpose of this prospective study is to investigate the influence of primary ESS in patients with CRS on self-reported and measured olfactory performance and to assess the role of preoperative disease severity in predicting outcome.

\section{Materials and methods}

The aim of this prospective study was to measure the association between preoperative CT imaging and the change in olfactory function as well as the subjective assessment of smell impairment after nasal surgery.

\section{Participants}

We included patients aged 16 years or more who underwent primary ESS for CRS with and without nasal polyps. The diagnosis of CRS was made according to criteria established by the EPOS
$2012^{(6)}$. Patients who suffered from immunodeficiency, cystic fibrosis, tumours such as inverted papilloma, or who presented for revision surgery were excluded from the study. The same applied to patients with a positive medical history of diseases with a potential impact on olfaction, except CRS. In all cases, preoperative medical management consisted of a topical nasal corticosteroid spray for at least four weeks.

Preoperatively, a total of ninety-two consecutive patients who met the eligibility criteria were enrolled in the study after giving informed consent. All of them had undergone a pre-treatment coronal CT scan which was evaluated referencing the LM system (range 0-24) ${ }^{(19)}$. The person who scored the CT scan was blinded to the olfactory test results.

On the basis of the LM score, the collective was divided into two groups. This limit was defined by the authors. Group A included subjects with $L M \leq 7$ (limited disease), reflecting less opacification in the CT scan, group B included patients with an LM score equal to or higher than eight $(L M \geq 8)$, indicating advanced or far advanced disease. Figure 1 shows an example of a limited CRS whereas Figure 2 shows a more advanced CRS. The ESS was adapted to the extension of the CRS starting with uncinectomy and anterior ethmoidectomy up to pansinus surgery with total ethmoidectomy, frontal sinus drainage Type I after Draf and sphenoidotomy ${ }^{(20)}$

Participants were examined preoperatively and on average five months postoperatively. All patients were treated postoperatively with saline solution and intranasal corticoids for at least eight weeks. Postoperatively, a total of 48 patients (Group A: 23; Group B: 25) could be followed-up.

\section{Smell testing}

The participants underwent the standardised olfactory test "Sniffin' Sticks" (12 odour kit, Burghart Company, Wedel, Germany), which is a well-investigated tool to assess olfactory function ${ }^{(21-23)}$. Twelve felt-tip pens filled with dissolved odorants were presented for bilateral testing. Patients had to identify

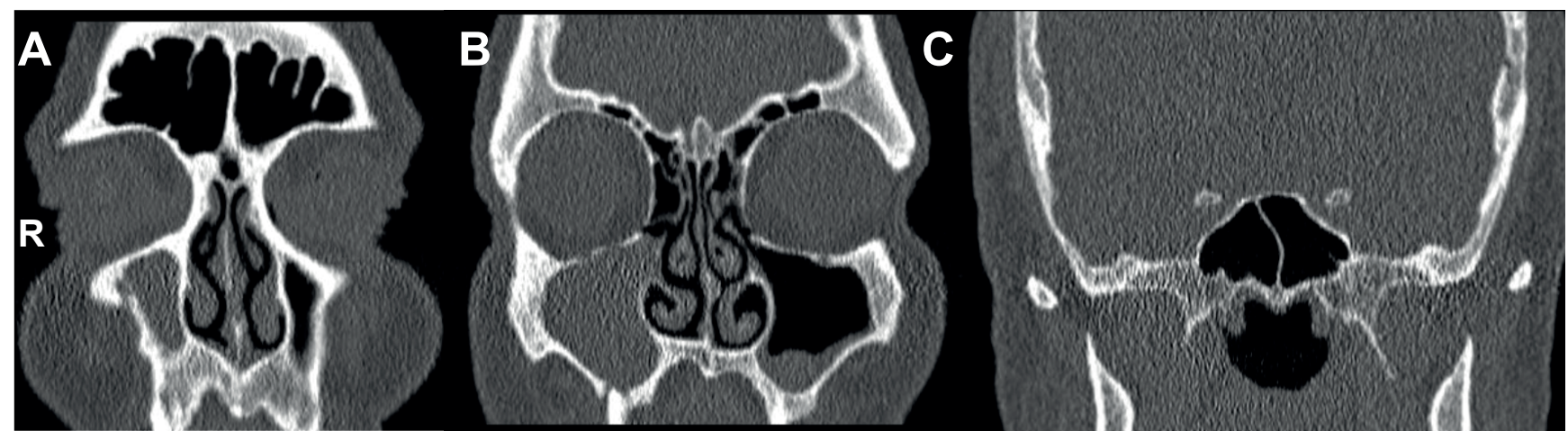

Figure 1. Example of a coronal CT scan showing a chronic rhinosinusitis with low Lund-Mackay-Score $(L M=5)$. A and B): Total opacification of the right maxillary sinus and right ostiomeatal complex (4 points) and partial opacification of the left maxillary sinus (1 point). No sign of inflammation in both frontal sinuses and ethmoid cells. C): No opacification of the sphenoid sinuses. 


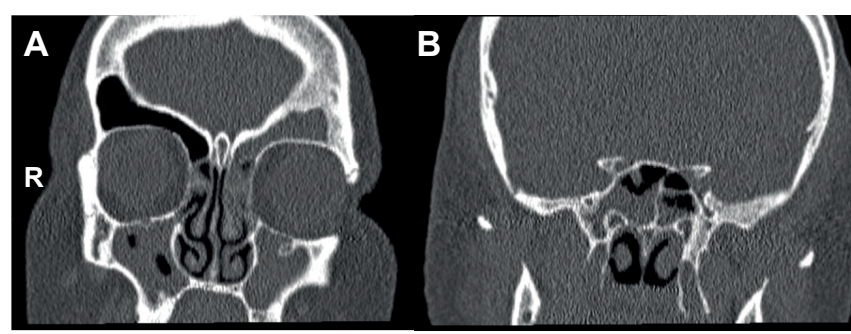

Figure 2. Example of a coronal CT scan showing a chronic rhinosinusitis with high Lund-Mackay-Score (LM = 15). A) Total opacification of the left frontal, maxillary and ethmoid sinuses with obstruction of the left ostiomeatal complex (10 points). Partial opacification of the right maxillary sinus and obstruction of the right ostiomeatal complex (3 points). B) Partial opacification of both sphenoid sinuses (2 points).

odours from a list of four descriptors using a multiple-forcedchoice task. Results ranged from zero to twelve, with high scores indicating better olfactory function.

\section{Rating of olfactory function and quality of life}

Additionally, participants were asked to complete the standardised, specific health-related quality of life questionnaire SNOT-20 German adapted version (GAV) (24-26). This validated questionnaire addresses 20 symptoms of CRS, including all major symptoms of the EPOS 2012 diagnostic criteria for CRS underneath smell impairment. Every symptom is represented by one item. Patients were asked to evaluate each symptom on a Likert scale from 0 (no problem) to 5 (problem as bad as it can be). The general symptom score is calculated by addition of the individual item scores and ranges from zero to 100. A high general score indicates a worse quality of life.

\section{Demographic and clinical data}

All participants underwent nasal endoscopy. Polyp size was assessed on a four-point scale: (0) no polyps diagnosed in nasal endoscopy; (1) mild polyps (small polyps not reaching the lower edge of the middle turbinate); (2) moderate polyps (mediumsized polyps extending between the upper and lower edges of the inferior turbinate); and (3) severe polyps (large polyps extending below the lower edge of the inferior turbinate) $)^{(27)}$. Point scores of both sides were added up to the total score. Further history of asthma, smoking, ASS-intolerance and allergies was also recorded.

\section{Statistical analyses}

Statistical analyses were performed using SPSS 20 (SPSS Inc., Chicago, IL, USA). To compare means, we used unpaired or paired $t$ tests as well as Wilcoxon test and Mann-Whitney- $U$ test, if appropriate. A two-tailed $P$ value of less than 0.05 was regarded as significant.

Ethics Committee Approval for this study was received from the

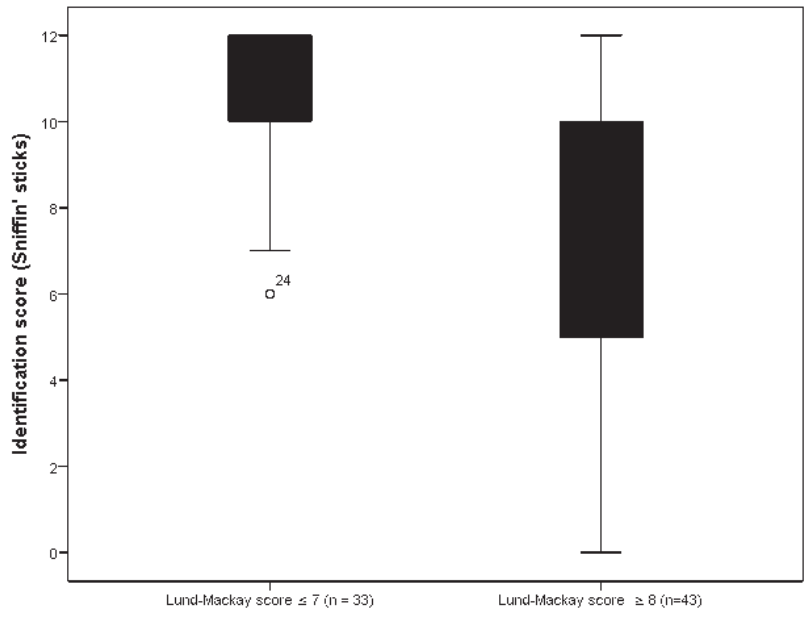

Figure 3. Preoperative results of sniffin' sticks test in group A and B.

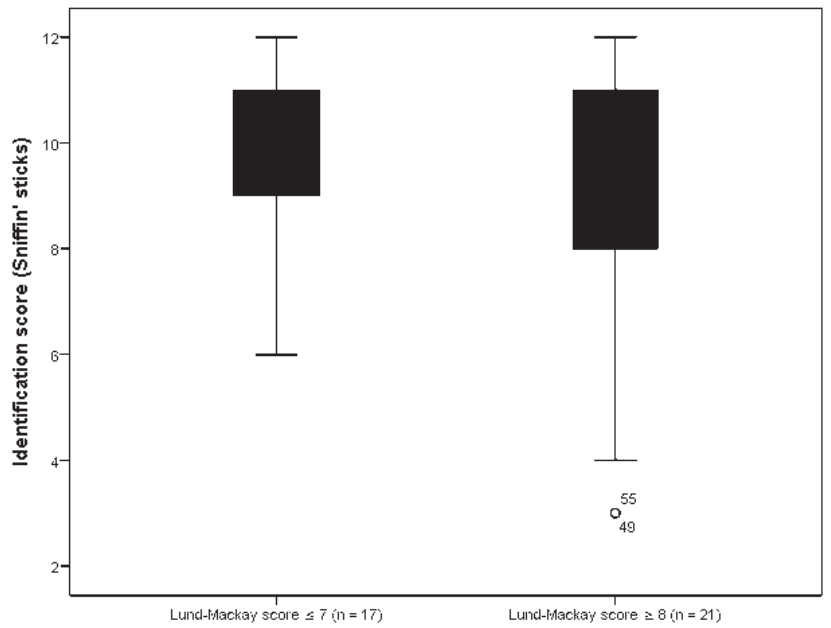

Figure 4. Postoperative results of sniffin' sticks test in group A and B.

local ethics committee (register number 3641-10).

\section{Results}

The patient collective included 92 patients with a mean age of $45.68 \pm 14.04$ years (range 16-72; median age 47.00 years). Fortyeight of these patients were seen pre- and postoperatively. The mean follow-up time period was 4.97 months (standard deviation (SD) 3.94 mo.). Patient characteristics are presented in Table 1 , separated by study group. There were no statistically significant differences related to the mentioned attributes between both groups, as proven by appropriate tests, exclusive of grade of nasal polyposis, which was significantly higher in group B.

\section{Sniffin' sticks tests results}

Smell test results were normally distributed at both measuring times. Comparing the difference of pre- and postoperatively obtained results of the "Sniffin' sticks" test, it could be demon- 
Table 1. Characteristics of investigated collective.

\begin{tabular}{|c|c|c|c|c|}
\hline & \multicolumn{2}{|c|}{$\begin{array}{l}\text { Lund-Mackay } \\
\text { score } \leq 7\end{array}$} & \multicolumn{2}{|c|}{$\begin{array}{l}\text { Lund-Mackay } \\
\text { score } \geq \mathbf{8}\end{array}$} \\
\hline & \multicolumn{2}{|c|}{ Group A $(n=43)$} & \multicolumn{2}{|c|}{ Group B $(n=49)$} \\
\hline & $\mathbf{N}$ & $\%$ & $\mathbf{N}$ & $\%$ \\
\hline Male & 24 & 55.8 & 32 & 65.3 \\
\hline Female & 19 & 44.2 & 17 & 34.7 \\
\hline Allergy & 18 & 41.9 & 21 & 42.9 \\
\hline Asthma & 8 & 18.6 & 9 & 18.4 \\
\hline ASS-intolerance & 0 & 0 & 1 & 2.0 \\
\hline \multirow[t]{2}{*}{ Smoker } & 19 & 44.2 & 16 & 32.7 \\
\hline & Mean & Range & Mean & Range \\
\hline Mean age in years & 43.00 & $16-72$ & 47.98 & $16-72$ \\
\hline (SD) & (15.02) & & (12.84) & \\
\hline $\begin{array}{l}\text { Mean degree of } \\
\text { polyposis }\end{array}$ & 0.86 & $0-6$ & 2.67 & $0-6$ \\
\hline (SD) & (1.51) & & (2.14) & \\
\hline
\end{tabular}

strated that olfactory function of patients with high LM score improved by an average of 2.49 points more than olfactory function of patients with low LM score (Table 2). This difference was statistically significant $(p=0.03)$.

We further evaluated the development of "Sniffin' sticks" test results in each group. Changes in olfactory performance were not statistically significant in either group, as demonstrated in Table 2.

Examining only patients suffering from objective hyposmia or anosmia preoperatively ("Sniffin' sticks" $<11$ ), we could found that olfactory function of group B improved significantly by about 2.77 points ( $p=0.015$; SD 4.18; paired t test; $n=17$ ), while olfactory function of patients in group $A$ did not show a significant change $(n=8)$. The grade of change also showed a significant difference of an average of -3.14 points $(p=0.015$; $95 \%-\mathrm{Cl}-5.6 ;-0.68$, unpaired t test).

Whisker-boxplots of pre- and postoperative results of the "Sniffin' sticks" test in both groups are presented in Figures 3 and 4. Preoperatively, a significant difference of 2.93 points could be shown between both mean scores. Postoperative difference was not significant (Table 3).

\section{Subjective evaluation of smell impairment}

Regarding perioperative development in terms of the selfreported rating of smell, the degree of change differed significantly between both groups. While patients of group B (higher preoperative LM score) showed a significant subjective improvement in olfactory function, the patients of group A did not show a significant alteration (Table 2). Prior to surgery, there was a statistically significant difference in favour of patients in group A, who reported less impairment of olfaction. Postoperative scores did not differ significantly (Table 3 ).

\section{Quality of life}

SNOT-20 GAV general scores were normally distributed pre(Group A: 36.25 vs. Group B: 38.74 ) and postoperatively (Group A: 18.04 vs. Group B: 15.72) in both groups.

Evaluating the general scores of SNOT-20 GAV, the degree of improvement of quality of life did not vary significantly between the two groups (Table 2). On average, the patients of both groups benefitted from ESS regarding quality of life, as a statistically significant decrease of general score was noted from the pre- to postoperative evaluation (Table 2). Both groups did not differ significantly in pre- and postoperative SNOT-20 GAV general scores (Table 3).

Table 2. Development of test scores in both groups (Baseline, Postoperative, and Net Change) after ESS.

\begin{tabular}{|c|c|c|c|c|c|c|c|c|}
\hline Test & Group & $\begin{array}{l}\text { Preopera- } \\
\text { tive score }\end{array}$ & $\begin{array}{l}\text { Postopera- } \\
\text { tive score }\end{array}$ & Change & p-value & $\begin{array}{l}\text { Difference } \\
\text { of changes }\end{array}$ & $95 \%-\mathrm{Cl}$ & p-value \\
\hline Sniffin' sticks test, & $\mathrm{LM} \leq 7(\mathrm{n}=17)$ & 10.59 (1.23) & $9.76(1.72)$ & $-0.82(1.7)$ & 0.064 & \multirow[b]{2}{*}{\}-2.49} & \multirow[b]{2}{*}{$-4.71 ;-0.27$} & \multirow[b]{2}{*}{0.03} \\
\hline Correct items (SD) & $L M \geq 8(n=21)$ & $7.48(4.0)$ & $9.14(2.85)$ & $1.67(4.59)$ & 0.111 & & & \\
\hline Rating of olfactory & $\mathrm{LM} \leq 7(\mathrm{n}=23)$ & $1.48(1.47)$ & $0.96(1.4)$ & -1.4 & -0.52 & \multirow[b]{2}{*}{ \} 1.40} & & \multirow[b]{2}{*}{0.024} \\
\hline Function, units (SD) & $L M \geq 8(n=25)$ & $3.08(1.85)$ & $1.16(1.41)$ & -3.49 & -1.92 & & & \\
\hline SNOT-20 GAV, General & $\mathrm{LM} \leq 7(\mathrm{n}=23)$ & $36.13(17.5)$ & $18.04(13.05)$ & $18.09(17.96)$ & $<0.001$ & \multirow{2}{*}{\}-7.32} & \multirow[t]{2}{*}{$-18.62 ; 3.99$} & \multirow[t]{2}{*}{0.199} \\
\hline Score (SD) & $L M \geq 8(n=25)$ & $41.04(16.81)$ & $15.72(11.53)$ & $25.32(20.77)$ & $<0.001$ & & & \\
\hline
\end{tabular}


Table 3. Comparison of mean scores in both groups before and after ESS.

\begin{tabular}{|c|c|c|c|c|c|c|c|c|c|c|c|}
\hline Test & Group & $\begin{array}{l}\text { Preope- } \\
\text { rative } \\
\text { score }\end{array}$ & SD & Diff. & $95 \%-\mathrm{Cl}$ & p-value & $\begin{array}{l}\text { Posto- } \\
\text { perative } \\
\text { score }\end{array}$ & SD & Diff. & $95 \%-\mathrm{Cl}$ & p-value \\
\hline Sniffin' sticks test (n) & $\begin{array}{l}\mathrm{LM} \leq 7 \\
\mathrm{LM} \geq 8\end{array}$ & $\begin{array}{l}10.39(33) \\
7.47(43)\end{array}$ & $\begin{array}{l}1.5 \\
3.71\end{array}$ & \} 2.93 & $1.68 ; 4.18$ & $<0.001$ & $\begin{array}{l}9.76(17) \\
9.14(21)\end{array}$ & $\begin{array}{l}1.72 \\
2.85\end{array}$ & 0.62 & $-0.9 ; 2.14$ & 0.412 \\
\hline $\begin{array}{l}\text { Smell impairment } \\
\text { subj. assessment ( } n \text { ) }\end{array}$ & $\begin{array}{l}L M \leq 7 \\
L M \geq 8\end{array}$ & $\begin{array}{l}1.36(42) \\
3.06(49)\end{array}$ & $\begin{array}{l}1.39 \\
1.74\end{array}$ & \}-1.70 & & $<0.001$ & $\begin{array}{l}0.96(23) \\
1.16(25)\end{array}$ & $\begin{array}{l}1.40 \\
1.41\end{array}$ & \}-0.20 & & 0.433 \\
\hline $\begin{array}{l}\text { General score } \\
\text { SNOT-20 GAV (n) }\end{array}$ & $\begin{array}{l}L M \leq 7 \\
L M \geq 8\end{array}$ & $36.25(42)$ & $\begin{array}{l}16.49 \\
16.24\end{array}$ & \}-2.49 & $-9.36 ; 4.38$ & 0.473 & $\begin{array}{l}18.04(23) \\
15.72(25)\end{array}$ & $\begin{array}{l}13.05 \\
11.53\end{array}$ & \} 2.32 & $-4.82 ; 9.47$ & 0.516 \\
\hline
\end{tabular}

\section{Discussion}

This prospective cohort study explored the postoperative improvement of olfactory function and its association with preoperative opacification in CT, and hence the severity of disease. We found that the mean olfactory function of patients with a high LM score improved more than olfactory function of patients with low LM score. This especially applied to patients with preoperative smell impairment. Patient's subjective perception of smell impairment was in line with these findings. Patients in group B showed improvement of self-reported rating of olfactory function postoperatively, while the patients in group A did not.

Confirming our results, Perry and Kountakis found high CT scores, as per LM, correlated with a greater improvement of olfactory function after ESS, even though smell impairment was only measured by self-reported rating in this study $(n=178)^{(16)}$. In a retrospective analysis of a group of fifty anosmic patients, Downey et al. showed less improvement of olfactory function in patients with CT-diagnosed mucosal disease extending beyond the ethmoid sinuses. However, no preoperative olfactory testing had been carried out ${ }^{(17)}$. Others could not show any correlation between preoperative LM score and olfactory improvement after surgery $(n=18 \text { and } n=70)^{(15,18)}$. In a recent publication by Baradaranfar et al., patients with an average LM-Score of 19.52 showed a significant improvement in olfaction with a combined therapy consisting of ESS and medical treatment ${ }^{(28)}$.

Litvack et al. demonstrated that, contrary to hyposmic or normosmic patients, patients with anosmia and nasal polyposis showed a significant improvement in olfactory testing 12 months postoperatively ${ }^{(14)}$; this evidence is supported by our results. Although we could not differentiate between hyposmic and anosmic patients due to small sample size (anosmics: $\mathrm{n}=$ 13; 12 with $L M \geq 8$ ), patients with smell impairment and high LM score improved significantly regarding olfactory function. However, in the mentioned study, LM score did not predict olfactory improvement after surgery ${ }^{(14)}$. Regarding anosmia and possible success of nasal surgery, similar results were previously obtained $^{(1)}$.

In their study, Katotomichelakis et al. also observed a significant improvement in olfactory function after ESS. Furthermore, they supposed poor preoperative olfactory function and nasal polyps to be a positive predictor in terms of improvement in patient's postoperative quality of life ${ }^{(29)}$.

Gudziol et al. described a postoperative improvement of olfactory function in patients with CRS, as well. Additionally, in this study they measured the olfactory bulb volume. Postoperatively an increase of olfactory bulb volume was observed. The change of odour threshold correlated with the change of olfactory bulb volume ${ }^{(30)}$.

\section{Further factors of influence}

Several further predictive factors have been proposed, such as a high grade of nasal polyposis, which seems to be a positive predictive factor ${ }^{(1,11,14,31)}$. Our study supports this hypothesis, as the grade of nasal polyposis was significantly higher in the group with high LM score. Age ${ }^{(11,14,31-32)}$ and gender ${ }^{(11,14,16,32)}$ have been ruled out as possible factors of influence on postoperative olfactory function. Perioperative medical treatment with topical ${ }^{(14,33)}$ or systemic steroid ${ }^{(14,34)}$ does not appear to have any influence on postoperative outcome in terms of olfactory function. The same is true for asthma ${ }^{(14,29)}$ and allergy $y^{(11,17,34)}$. There were no statistically significant differences related to these factors between both groups in our study. Thus, an influence on postoperative results is unlikely.

Our results suggest that the degree of opacification in the preoperative CT scan can be a predictor for postoperative olfactory function in patients with preoperative smell impairment. The same seems to apply to the grade of nasal polyposis, while we assume that there is a positive correlation between degree of nasal polyposis and opacification in CT scan.

Assuming that there is a positive correlation between degree 
of nasal polyposis and opacification in $\mathrm{CT}$, a number of other studies support our findings.

Pade et al. examined 206 patients suffering from CRS with the aid of the "Sniffin' sticks" test before and four months after surgery. They found that patients with nasal polyposis had a significantly higher benefit from surgery concerning olfactory function ${ }^{(11)}$. Schriever et al. confirmed that patients with CRS and nasal polyps are more likely to improve olfactory function after nasal surgery than other patients undergoing nasal surgery ${ }^{(35)}$. Two further studies demonstrated an improvement in olfactory function after ESS in patients with nasal polyposis ${ }^{(36,37)}$.

Although the follow-up time in this study is relatively short, our study could show some interesting short-term results concerning olfaction and quality of life after ESS. In terms of olfactory function, patients with a high LM score seemed to profit more from primary sinus surgery than patients with LM $\leq 7$. Prior to surgery, there was a significant difference between both groups in the "Sniffin' sticks" test results and self-reported rating of smell impairment. Specific health-related quality of life improved in both groups, irrespective of LM score. Our study proves that patients with a limited disease (low LM score) also showed an improvement in the quality of life after primary ESS. One strength of our study was that we exclusively studied patients who had no previous sinus surgeries. As reported by Danielides et al., previous sinus surgery has a strong negative predictive value on olfactory performance after ESS ${ }^{(38)}$. Hence, it is important to distinguish between patients with or without previous sinus surgery when analysing the effect of surgery on olfactory function. On the other hand, our study has some limitations, as we lost some patients during the follow-up period. Due to the strict inclusion criteria, not all patients who were operated on in our department could be included in the study. Existing studies exploring the improvement of olfactory impairment after sinus surgery are largely inhomogeneous; they use a multitude of both self-reported ratings of olfactory function and quantitative olfactory tests, the definition of improvement varies among studies, the extent of surgery often remains unclear, sample sizes are mostly small and perioperative medical treatment is not defined.

\section{Conclusion}

In conclusion, our prospective study showed that primary ESS has a positive influence on the quality of life, independent of disease severity. Concerning olfactory function, patients with a more expanded disease reached better olfactory improvement after surgery.

\section{Acknowledgements}

We would like to thank R. Klaaßen-Mielke, Department of Medical Informatics, Statistics and Epidemiology, Ruhr-University Bochum, Germany, for her assistance with the statistical analysis.

\section{Authorship contribution}

FM, primary investigator: study design, patient work, data collection and analysis, manuscript writing; JPT: data collection, manuscript writing; MB-S: manuscript writing, data analysis; SD: study supervision, manuscript writing; AM: study design, patient work, data analysis, manuscript writing.

\section{Conflicts of Interest}

No conflict of interest.

\section{References}

1. Delank KW, Stoll W. Olfactory function after functional endoscopic sinus surgery for chronic sinusitis. Rhinology 1998; 36: 15-19.

2. Damm M, Temmel A, Welge-Lussen A, et al. Olfactory dysfunctions. Epidemiology, and therapy in Germany, Austria and Switzerland. HNO. 2004; 52: 112-120.

3. Holbrook EH, Leopold DA. Anosmia: diagnosis and management. Curr Opin Otolaryngol Head Neck Surg. 2003; 11 : 54-60.

4. Temmel AFP, Quint C, SchickingerFischer B, Klimek L, Stoller E, Hummel T. Characteristics of olfactory disorders in relation to major causes of olfactory loss. Arch Otolaryngol Head Neck Surg. 2002; 128: 635-641.

5. Litvack JR, Fong K, Mace J, James KE, Smith TL. Predictors of olfactory dysfunction in patients with chronic rhinosinusitis. Laryngoscope. 2008; 118: 2225-2230.

6. Fokkens WJ, Lund VJ, Mullol J, et al. European position paper on rhinosinusitis and nasal polyps 2012. Rhinol Suppl 23, $1-299$.

7. Litvack JR, Mace JC, Smith TL. Olfactory function and disease severity in chronic rhinosinusitis. Am J Rhinol Allergy. 2009; 23: 139-144.

8. Raviv JR, Kern RC. Chronic rhinosinusitis and olfactory dysfunction. Adv Otorhinolaryngol. 2006; 63: 108-124

9. Miwa T, Furukawa M, Tsukatani T, Costanzo RM, DiNardo LJ, Reiter ER. Impact of olfactory impairment on quality of life and disability. Arch Otolaryngol Head Neck Surg. 2001; 127: 497-503.

10. Brämerson A, Nordin S, Bende M. Clinical experience with patients with olfactory complaints, and their quality of life. Acta Oto-Laryngologica. 2007; 127: 167-174.

11. Pade J, Hummel T. Olfactory function following nasal surgery. Laryngoscope. 2008; 118: 1260-1264.

12. Briner HR, Jones $N$, Simmen D. Olfaction after endoscopic sinus surgery: long-term results. Rhinology 2012; 50: 178-184.
13. Landis BH, Hummel T, Hugentobler M, et al. Ratings of overall olfactory function. Chem Senses. 2003; 28: 691-694.

14. Litvack JR, Mace J, Smith TL. Does olfactory function improve after endoscopic sinus surgery? Otolaryngol Head Neck Surg. 2009; 140: 312-319.

15. Konstantinidis I, Triaridis S, Printza A, Vital V, Ferekidis E, Constantinidis J. Olfactory dysfunction in nasal polyposis: correlation with computed tomography findings. ORL. 2007; 69: 226-232.

16. Perry BF, Kountakis SE. Subjective improvement of olfactory function after endoscopic sinus surgery for chronic rhinosinusitis. Am J Otolaryngol. 2003; 24: 366-369.

17. Downey LL, Jacobs JB, Lebowitz RA. Anosmia and chronic sinus disease. Otolaryngol Head Neck Surg. 1996; 115: 24-8.

18. Jiang RS, Su MC, Liang KL, et al. Preoperative prognostic factors for olfactory change after functional endoscopic sinus surgery. Am J Rhinol Allergy. 2009; 23: 64-70. 
19. Lund VJ, Mackay IS. Staging in rhinosinusitis. Rhinology. 1993; 107: 183-184

20. Draf W. Endonasal micro-endoscopic frontal sinus surgery. The Fulda concept. Op Tech Otolaryngol Head Neck Surg. 1991; 2: 234240.

21. Hummel T, Konnerth CG, Rosenheim K, Kobal G. Screening of olfactory function with a four minute odour identification test: reliability, normative data, and investigations in patients with olfactory loss. Ann Otol Rhinol Laryngol. 2001; 110: 976-981.

22. Hummel T, Sekinger B, Wolf SR, Pauli E, Kobal G. "Sniffin' sticks": olfactory performance assessed by the combined testing of odour identification, odour discrimination and olfactory threshold. Chem Senses. 1997; 22: 39-52

23. Kobal G, Klimek L, Wolfensberger M. Multicentre investigation of 1,036 subjects using a standardised method for the assessment of olfactory function combining tests of odour identification, odour discrimination, and olfactory thresholds. Eur Arch Otorhinolaryngol. 2000; 257: 205-211.

24. Piccirillo JF, Merritt MG, Richards ML. Psychometric and clinimetric validity of the 20-Item Sino-Nasal Outcome Test (SNOT20). Otolaryngol Head Neck Surg. 2002; 126: 41-47.

25. Baumann I, Blumenstock G, De Maddalena H, Piccirillo JF, Plinkert PK. Quality of life in patients with chronic rhinosinusitis. Validation of the Sino-Nasal Outcome Test20 German Adapted Version. HNO. 2007; 55: 42-47.

26. Baumann I, Plinkert PK, De Maddalena H. Development of a grading scale for the
Sino-Nasal Outcome Test-20 German Adapted Version (SNOT-20 GAV). HNO. 2008; 56: 784-788.

27. Bonfils P. Evaluation of the combined medical and surgical treatment in nasal polyposis. I: Functional results. Acta OtoLaryngologica. 2007; 127: 436-446.

28. Baradaranfar MH, Ahmadi ZS, Dadgarnia $\mathrm{MH}$, et al. Comparison of the effect of endoscopic sinus surgery versus medical therapy on olfaction in nasal polyposis. Eur Arch Otorhinolaryngol. 2014; 271:311-316.

29. Katotomichelakis M, Simopoulos $E_{\text {, }}$ Tripsianis G, et al. Predictors of quality of life outcomes in chronic rhinosinusitis after sinus surgery. Eur Arch Otorhinolaryngol. 2014; 271: 733-741.

30. Gudziol V, Buschüter D, Abolmaali N, Gerber J, Rombaux P, Hummel T. Increasing olfactory bulb volume due to treatment of chronic rhinosinusitis--a longitudinal study. Brain. 2009; 132: 3096-3101.

31. Minovi A, Hummel T, Ural A, et al. Predictors of the outcome of nasal surgery in terms of olfactory function. Eur Arch Otorhinolaryngol. 2008; 265: 57-61.

32. Kimmelmann CP. The risk to olfaction from nasal surgery. Laryngoscope. 1994; 104: 981-988.

33. Ehnhage A, Olsson P, Kölbeck KG, et al. Functional endoscopic sinus surgery improved asthma symptoms as well as PEFR and olfaction in patients with nasal polyposis. Allergy. 2009; 64: 762-769.

34. Federspil PA, Wilhelm-Schwenk $R$, Constantinidis $J$. Kinetics of olfactory function following endonasal sinus surgery for nasal polyposis. Rhinology. 2008; 46: 184 -
187

35. Schriever VA, Gupta N, Pade J, et al. Olfactory function following nasal surgery: a 1-year follow-up. Eur Arch Otorhinolaryngol. 2013; 270: 107-111.

36. Olsson P, Stjärne P. Endoscopic Sinus Surgery improves olfaction in nasal polyposis, a multi-center study. Rhinology. 2010; 48: 150-155

37. Enhage A, Olsson P, Kölbeck KG, et al. One year after endoscopic sinus surgery in polyposis: Asthma, olfaction and quality-of-life outcomes. Otolaryngol Head and Neck Surg. 2012; 146: 834-841.

38. Danielides $V$, Katotomichelakis $M$, Balatsouras D, et al. Evaluation of prognostic factors for olfaction in nasal polyposis treated by Endoscopic Sinus Surgery. Rhinology. 2009; 47: 172-180

\section{Amir Minovi}

Department of Otorhinolaryngology

Head and Neck Surgery

Ruhr-University Bochum

St. Elisabeth Hospital

Bleichstr. 15

44787 Bochum Germany

Tel: +49-234-508-8281

Fax: +49-234-508-8279

E-mail:amir.minovi@rub.de 